\title{
Correction to: Creating a "family tree" on fertilizer inventory use in life cycle assessment of oil palm: visualization of earlier studies and its implications
}

\section{Kiyotada Hayashi ${ }^{1}$}

Published online: 27 May 2019

(C) Springer-Verlag GmbH Germany, part of Springer Nature 2019

\section{Correction to: Int J Life Cycle Assess.}

https://doi.org/10.1007/s11367-019-01607-9

The original version of this article unfortunately contained a mistake.

One grant number in the Funding Information section was incorrect. The correct version of the Funding information section is given below.

\section{Funding information}

This work was in part supported by the Japan Society for the Promotion of Science, Grant-in-Aid for Scientific Research (KAKENHI) grant number 26310316 and $18 \mathrm{~K} 11745$.

Publisher's note Springer Nature remains neutral with regard to jurisdictional claims in published maps and institutional affiliations.

The online version of the original article can be found at https://doi.org/ 10.1007/s11367-019-01607-9

Kiyotada Hayashi

hayashi@affrc.go.jp

1 Institute for Agro-Environmental Sciences, National Agriculture and Food Research Organization, 3-1-3 Kannondai, Tsukuba,

Ibaraki 305-8604, Japan 